\title{
Semi-professionals: emergency response as an additional task in current occupations
}

Kayvan Yousefi Mojir, Sofie Pilemalm and Tobias Andersson Granberg

The self-archived postprint version of this journal article is available at Linköping University Institutional Repository (DiVA):

http:/ / urn.kb.se/ resolve?urn=urn:nbn:se:liu:diva-150834

N.B.: When citing this work, cite the original publication.

Yousefi Mojir, K., Pilemalm, S., Andersson Granberg, T., (2018), Semi-professionals: emergency response as an additional task in current occupations, International J ournal of Emergency Services. https:/ / doi.org/ 10.1108/ IJ ES-11-2017-0059

Original publication available at:

https:// doi.org/ 10.1108/ IJ ES-11-2017-0059

Copyright: Emerald

http:// www.emeraldinsight.com/ 


\title{
Semi-professionals: Emergency response as an additional task in current occupations
}

\author{
Kayvan Yousefi Mojir \\ kayvan.y.mojir@liu.se \\ Department of Management and Engineering, Linköping University, Linköping, Sweden \\ Sofie Pilemalm \\ sofie.pilemalm@liu.se \\ Department of Management and Engineering, Linköping University, Linköping, Sweden
}

Tobias Andersson Granberg
Division of Communication and Transport Systems (ITN), Linköping University, Linköping, Sweden

\section{ABSTRACT}

\section{Purpose}

This study aims at 1) identifying occupational groups who can act as semi-professional first responders, in order to shorten the response times for frequent emergencies, and 2) identifying related opportunities, challenges, and needs of training, emergency supplies and IT support.

\section{Design/methodology/approach}

A case study approach was taken, combining future workshops, focus groups, and an exercise. Network governance was used as an analytical lens.

\section{Findings}

The results show that semi-professionals have a large potential to complement professional resources by carrying out first response or supportive actions vital to the emergency, partly by using already existing cars and equipment. The identified potential groups are security guards, home care personnel, fire services day personnel, and facility service personnel. The identified needs include additional basic equipment such as fire extinguishers and first-aid kits, training in basic firefighting, first aid and risk assessment, as well as mobile phone applicationbased IT support to manage alarms. The major challenges are organisational, economic and juridical, and ambiguities in responsibilities and related insurances. The analysis recognises the new collaboration as a hybrid form of hierarchical government and network governance.

\section{Social/practical implications}

The study suggests that using semi-professional resources can be one of many innovative solutions to recent public sector challenges that have put a huge strain on professional emergency response organisations.

\section{Originality/value}

The study provides a novel view of using semi-professional resources in emergency response, based on the joint perspectives of various occupational groups, and the fire services.

\section{KEYWORDS}

Cross-sector collaboration with fire services, semi-professionals, network governance

Yousefi Mojir, K., Pilemalm, S., \& Andersson Granberg, T. (2018) Semi-professionals: emergency response as an additional task in current occupations, International Journal of Emergency Services, https://doi.org/10.1108/IJES11-2017-0059. 


\section{INTRODUCTION}

Governments have become increasingly dependent on creating and maintaining redundancy in societal resources to achieve their goals in times of public challenges, for example resource shortages, budget cuts, migration, urbanisation, an ageing population, and many others (Agranoff, 2007; O'Leary and Bingham, 2009). As one response to the challenges, horizontal government structures (vs. traditional top-down government) have emerged in which various actors are included in policymaking and service delivery, in what is usually referred to as network governance forms (Jones et al., 1997). Emerging network initiatives can be seen not least in the area of emergency response systems (ERS), i.e., systems aimed at saving lives and minimising human suffering and material damage in small-scale emergencies as well as largescale crises and catastrophes.

Many ERSs rely increasingly on co-operative use of resources, by shareing equipment, competencies and capacities or involving other on-call societal resources to collaborate with professional response resources, for example the fire services (Weinholt and Andersson Granberg, 2015; Kapucu et al., 2010; Sund, 2006; Valenzuela et al., 2000). In relation to ERS cross-sector collaborations, different studies have focused, on the medical aspects (Weisfeldt et al., 2010), economic aspects (Weinholt and Andersson Granberg, 2015), technological improvement (Jaeger et al., 2007) or on the effect of the collaborations (Drezner et al., 2009). These studies are mainly in relation to large-scale emergencies and ad-hoc organisation. However, the establishment of permanent cross-sector collaboration as the first response to frequent accidents (for example traffic accidents and fires) is still a rather recent research area. Examples of identified challenges and needs are the ambiguities in new actors' tasks, balance in responsibilities, utilising different pooled competencies, training needs, information technology (IT) support and legal issues (e.g., Yousefi Mojir and Pilemalm, 2016; Fischer et al., 2011; Palm and Törnqvist, 2008; Pelinka et al., 2004 ). Since emergency responses are many times ultimately about saving lives and minimising human suffering, any failure in related collaboration can risk victims' lives and put huge mental pressure on first responders. Therefore, more detailed studies of opportunities, challenges and actor needs, are urgently required.

\section{STUDY AIM}

In this study, we address the establishment of cross-sector collaboration in daily emergency response in Sweden. Specifically, the study aims are to:

o identify occupational groups that have the possibility and capacity to be involved in crosssector collaboration network forms of emergency response;

○ identify opportunities, challenges, and actor needs (for example training, equipment and information technology).

Since ERSs worldwide share many characteristics, resources and information technology (IT) tools, the studies primary target group is researchers who work with emerging collaboration forms within ERSs. We also discuss aspects of how to implement cross-sector collaborations. Therefore, the study may also be used by practitioners in the development of potential ERSs 
cross-sector collaborations. As emerging cross-sector collaborations in ERSs in many respects share characteristics with and resemble principles in network governance, we use the latter as an analytical lens. In this way, we can assess the relevance of network governance as theoretical support when addressing success factors and challenges in future cross-sector collaborations.

\section{BACKGROUND}

In this section, we give a short overview of the cross-sector collaboration concept, followed by a description of recent Swedish emergency response initiatives and the study context.

\subsection{Cross-sector collaboration initiatives in the public sector}

A societal sector can be seen as the collection of actors (for example public, private, nonprofits, and volunteers) whose goals are similar or related to each other. In our study, the public sector refers to all governmental actors providing public services. The definition of collaboration in general by Thomson and Perry (2006) and of cross-sector collaboration by Bryson et al. (2006) are used together since they focus on sharing resources and the performance of joint activity by autonomous resources. We thus define cross-sector collaboration in emergency response as:

a process in which different autonomous actors from different societal sectors attempt to create a new setting by establishing new ways of sharing information, resources and capabilities and by performing joint response operations in order to achieve common goals, including saving lives and minimising environmental damages.

Cross-sector collaboration initiatives are commonly aimed at coping with current public challenges. To address public health (rising rate of chronical disease, obesity, ageing population; Johnston and Finegood, 2015), to control traffic congestion in metropolitan areas (Bryson et al., 2009), to cope with climate change (Ingold and Fischer, 2014) and to secure food management to overcome poverty (Hamann et al., 2011) are but a few examples. The collaboration actors can include, the private sector, non-governmental organisations, volunteers or citizens in the delivery of services. Greater efficiency, redundancy in societal systems, higher quality of services, and improved organisational accountability are some examples of the perceived benefits (Alford and O'Flynn, 2012; Brinkerhoff, 2002). However, different studies also argue that it is no easy task to achieve cross-sector collaborations (Bryson et al., 2006; Greve and Hodge, 2005). Several researchers have pointed to challenges such as distrust, managerial complexity, cultural conflict, power imbalance, the risk of dependence, and lack of incentive for collaborating (Babiak and Thibault, 2009; Gazley and Brudney, 2007).

\subsection{Changing Emergency response systems and emerging cross-sector initiatives in Sweden}

Emergency response systems (ERSs) consist of professional response organisations (for example fire services, ambulance services, alarm centre) and aim at saving lives and mitigating environmental damages in frequent small emergencies and large-scale crises (for example flooding, storms or earthquakes). In most countries, an ERS is part of the public sector since the municipalities or state often employs the main resources. There are various 
studies in emergency response that have focused on cross-sector collaboration (e.g., Kapucu et al., 2010; Waugh and Streib, 2006). One example is the use of security officers in the US to assist in life-threatening emergencies (Valenzuela et al., 2000). Patton (2007) listed several possible groups that can be helpful to complete and strengthen local capacities to deal with emergencies, for example subject-matter experts, community-based organisations, social service agencies, civic groups, private businesses, and media organisations. However, more detailed studies exploring related challenges and opportunities in depth seem mostly absent in the research literature.

The last couple of years, a number of Swedish initiatives have emerged aiming to involve nontraditional actors in emergency response. These include private persons, non-profit organisations, clubs, and occupational groups that, in theory, can assist professional resources (see for example Ramsell et al. 2017; Pilemalm et al., 2016a; Yousefi Mojir and Pilemalm, 2014). In the specific case of cross-sector collaboration, the fire services in some municipalities collaborate with security guards otherwise employed by private companies. The security guards can perform first response at a variety of events and assist professional resources (Weinholt and Andersson Granberg, 2015). The municipality of Nyköping has implemented the co-operative use of equipment and a joint alarm centre for fire services and social care resources (Pilemalm et al., 2016a). In the SALSA project, certain resources (for example taxi drivers) were equipped with defibrillators to help people suffering from cardiac arrest (Hollenberg et al., 2009).

\subsection{Study context}

The Efficient communal use of municipal resources for increased safety and security" (ESKORT) project aimed to introduce emergency response cross-sector collaboration in the municipality of Norrköping in Sweden. It is based on the concept of co-operative use of resources, in which it is assumed that certain occupations, described as semi-professionals, can partake in response operations. Semi-professionals' primary profession is not in emergency response but they might be on-call resources ready to respond to new, incoming tasks, and may have equipment such as vehicles and communication devices that can be used in response operations. They can intervene in an emergency, either to assist professional first responders or to act as first responders themselves. The project set out to identify potential groups of semi-professionals, select the most suitable, identify opportunities, challenges and needs of equipment and training, provide checklists and information technology support for the alarm process, and eventually perform initial tests with the semi-professionals. The project started in early 2015 and was finished in April 2017. Our study focuses specifically on collaboration opportunities, challenges and actor needs in the emerging collaboration.

\section{THEORETICAL FRAMEWORK}

This section shortly describes relevant network governance concepts.

\subsection{Network Governance}

Network governance exists in different research domains such as political science, public administration and for studying inter-organisational relationships. New public management, 
public-private partnerships, stakeholder and citizen involvement, network societies, horizontal interactive decision-making, and public sector innovation are examples of study objects (Klijn and Koppenjan, 2012; Pilemalm et al., 2016b). There is no consensus among scholars whether all the forms described present a network governance form (Klijn, 2008). However, a set of common principles and key factors in the research literature are recurrently used to characterise network governance. The key factors that we identified as relevant to the study are gathered, summarised and shown in Table 1 together with the network governance core principles.

Table 1. Principles and key factors in network governance identified as relevant for the study analysis

\begin{tabular}{|l|l|}
\hline Network governance & $\begin{array}{l}\text { Autonomous actors interact to make policies and perform service delivery in an } \\
\text { horizontal pattern without any clear top-down governing mechanism based on mutual } \\
\text { interests or contracts (Jones et al., 1997). The outcome of a network is a result of the } \\
\text { interaction of many actors' responses to complicated problems that are difficult to } \\
\text { handle by a single actor (Klijn and Koppenjan, 2012). }\end{array}$ \\
\hline Key factors: collaboration \\
and decision-making & $\begin{array}{l}\text { Collaborative action and complex problem solving with heterogeneous resources, } \\
\text { democratic and horizontal decision-making, equal priority in interactions between } \\
\text { members (Jones et al., 1997; Rhodes, 1996; Powell, 1990). }\end{array}$ \\
\hline Key factor: trust & $\begin{array}{l}\text { Trust can be defined as a stable positive expectation in which actors expect each other } \\
\text { to refrain from opportunistic behaviour even if the opportunity arises and to take each } \\
\text { others' interests into account in interactions (Klijn et al., 2010). Trust is a facilitator } \\
\text { for collaboration in networks. For example, information sharing is only possible if } \\
\text { trust exists, while the absence of trust causes complexities in a network, for example } \\
\text { resulting in lack of information exchange (Klijn et al., 2010). }\end{array}$ \\
\hline $\begin{array}{l}\text { Key factors: conflicts and } \\
\text { institutional rules }\end{array}$ & $\begin{array}{l}\text { Interactions between members are complex because of their various and sometimes } \\
\text { conflicting interests and strategies and members different perceptions of the } \\
\text { information/problem/context. Institutional rules also may compete and cause conflicts } \\
\text { in the members' interactions (Klijn and Koppenjan, 2014; Weber and Khademian, } \\
\text { 2008). }\end{array}$
\end{tabular}

\subsection{Applying network governance}

'Network governance' and 'cross-sector collaboration' are sometimes used interchangeably in the literature (e.g., Agranoff, 2007). In our study, the focus is on collaboration between sectors and involved actors that are autonomous, have their own organisational rules and are not managed directly by the professional resources. There is thus no clear top-down governing mechanism as is also the case in network governance (Rhodes, 1996). Trust and distrust as key factors have been discussed extensively in both network governance and crosssector collaboration. Other challenges such the risk of dependence, difficulty in information sharing, managerial complexities and organisational conflict have also been observed (Babiak and Thibault, 2009; Klijn and Koppenjan, 2014).

More specifically, the semi-professionals come from sectors (both public and private organizations) other than emergency response, are autonomous and have their own organisations. They are given limited responsibility and power to decide and act in response operations as a complement to, and together with, professional response organisations. Semiprofessionals thus collaborate with a number of actors such as fire services, emergency 
medical services, alarm centres and possibly other types of semi-professionals (occupational groups) or volunteers. The work entails collective problem-solving led by the rescue services. Therefore, the study is viewed as an example of cross-sector collaboration, which in turn can be seen as an instantiation of network governance. In our analysis, network governance is used as a context and overall framework for analysis to put the results in a wider context and explore its usefulness when developing ERS cross-sector collaborations.

\section{RESEARCH METHODOLOGY}

This section describes the studies overall research methodology and data collection methods.

\subsection{Case study and participatory action research}

A qualitative interpretive approach and case study research methodology (Myers, 2009) were applied. Case studies seek to study real social, organisational, or political phenomena (Stake, 2000). The studied case is the development of cross-sector collaboration in the Swedish ERS as an instantiation of public sector network governance. Accordingly, the case is understood through social construction and the meaning people bring to the study object, for example through interviews, workshops and meetings. The main advantage of case study research is that it yields detailed insights into a social phenomenon in a complex real-life situation. A common critique is that the acquired knowledge is not generalizable when a study is limited to one or a few cases (Myers, 2009). Therefore, a general framework, i.e. the network governance, is used as a base when trying to draw more general conclusions from the results.

The study is also inspired by participatory action research (PAR; Reason and Bradbury, 2013), in which the interaction between researchers and other relevant actors is central. Researchers and stakeholders participate actively and jointly in work groups to improve the results. In our study, a project core group was formed and additional stakeholders and users were subsequently and actively involved, as described below. The core group included the project manager, a research group of four researchers, a representative from the fire services, a representative from the municipality and a representative from an IT company. Three of the involved researchers carried out the study. The data was gathered by one of the researchers, who also was mainly responsible for the analysis, had developed the context-specific framework, and is the primary author of this paper. The other two researchers/authors then provided feedback on the retrospective interpretative analysis, for example in terms of whether they agreed on the challenges identified, why they occurred and how they had been handled, and with what result.

\subsection{Data Collection Process}

The project core group initially identified four potential groups of semi-professionals among many candidates. Representatives from the four groups were interviewed to identify challenges, opportunities and initial needs for support. Based on the interview results, a final group was selected and involved in a more thorough needs analysis using a Future Workshop and an exercise in the form of a simulated traffic accident. Below, we describe the different steps of the study in more detail. 
Step 1. An introductory Future Workshop was held with relevant participants identified by the project core group (Table 2). The aim was to discuss and identify the possibilities and limitations of various occupational groups and choose possible candidates for the potential cross-sector collaboration. Jungk and Müller (1987) developed the concept of Future Workshops as a technique to allow participants to reflect upon their current work situation and develop innovative ideas to enhance it. Since the intended cross-collaboration context was new to the participants and related work tasks not defined, a somewhat adapted version of the concept was applied. Two moderators (researchers) presented a short description of the project and also provided an initial list of potential occupational groups (for example school personnel, facility services, the church, social care personnel, energy firms, security guards) and types of emergencies (for example fires, traffic accidents and heart failures) to trigger a discussion among the participants. Then each group discussed a variety of situations such as drownings, traffic accidents, floods, vandalism, fire in buildings, and persons stuck in snow, in which cross-sector collaboration can be helpful. Subsequently, the participants were asked to select and prioritise potential semi-professional groups. The participants made notes on Post-It notes, the researchers took notes and the discussions were audio-recoded. The project core group performed the final selection of candidates for further analysis. The selection consisted of security guards, home care personnel, fire services day personnel, and private entrepreneurs (facility services).

Step 2. Following the Future Workshop, the researchers held focus group interviews with 13 representatives from the four selected candidates (Table 2). Four interviews were with operative personnel from the respective groups and two interviews were with managers. Each interview took roughly one and a half hours. The interviews were audio-recorded and transcribed. The purpose of focus group interviews is to get collective views on certain phenomenon from a group of people who have certain interests, experience or knowledge concerning the topic (Myers, 2009). Thus, they covered the opinions of the interviewees about new cross-sector collaborations, including opportunities, challenges and related needs. After the interviews, the project core group found fire service day personnel the most appropriate in the current context and they were thus selected for further needs analysis. Based on the focus group interviews, an initial needs list was produced.

Step 3. An additional whole day Future Workshop (see Table 2) was held with fire service day personnel participants to allow the selected final candidates to reflect upon the intended new setting, develop innovative ideas and discuss organisationally and technically feasible implementations. The specific aim was to complete the needs list. The focus was on needs for training, equipment and information technology support, while, for example, needs for changes in laws and regulations were only briefly discussed. The participants wrote their ideas down on paper, the researchers took notes and the discussions were audio-recoded.

Step 4. A smartphone application was prototyped from the extracted initial needs and was also reviewed in the second workshop. The revised and completed needs were formulated as checklists and evaluated in a simulated car accident/exercise with two victims. Two semiprofessionals/fire service day personnel, the rescue services and the ambulance services were sent on the alarm. Three researchers observed the semi-professionals arriving at and working 
at the emergency site (about 15 minutes before the professional resources arrived) and held an After Action Review (AAR) with all the participants (Table 2). AAR hails from the military domain and is a learning method to capture and reflect upon the strength and weaknesses of past events, in order to prepare for future situations (Bolton, 2016). The results were updated and as a final validation, they were sent to an external fire service organisation, with long experience of utilising semi-professional resources, who could verify that the results seemed reasonable.

Table 2. Summary of data collection activities

\begin{tabular}{|c|c|}
\hline Data collection activity & Participants \\
\hline Future Workshop 1 & $\begin{array}{l}\text { Four researchers, three representatives from the fire services, three from the municipality, } \\
\text { one from the police and one from the healthcare sector }\end{array}$ \\
\hline Focus group interview 1 & Three respondents from fire service day personnel + three researchers \\
\hline Focus group interview 2 & Four respondents from home care + two researchers \\
\hline Focus group interview 3 & Two respondents from facility services + two researchers \\
\hline Focus group interview 4 & Three respondents security guards + two researchers \\
\hline Focus group interview 5 & Fire service management + home care management + two researchers \\
\hline Focus group interview 6 & Facility service management + security guards management + two researchers \\
\hline Future Workshop 2 & $\begin{array}{l}\text { Three fire service day personnel as main end-users }+ \text { a representative from fire services }+ \\
\text { three researchers }\end{array}$ \\
\hline $\begin{array}{r}\text { Exercise }+ \text { After Action } \\
\text { Review }(\mathbf{A R R})\end{array}$ & $\begin{array}{l}\text { A simulated traffic accidents, with two semi-professionals, and three researchers as } \\
\text { observers }\end{array}$ \\
\hline
\end{tabular}

\subsection{Data Analysis}

A coding approach (Myers, 2009), also called thematic analysis, was used. The data was first organised in text units (for example transcribed interviews) and was read to get a sense of the whole before breaking it down into parts. The data was then categorised into four themes: 1) Responsibility, availability and attitude, 2) Laws, regulations and work environment, 3) Training and emergency supply, 4) Information Technology and communication. According to Myers (2009), themes can be derived from the data itself or existing literature. Here, themes stem from a framework that we have explicitly developed for case analysis in the emergency response context (Yousefi Mojir, et al., 2016) and which has been used several times before. In the next step, the data in each of the themes was divided into opportunities, challenges, and actor needs. Finally, an additional thematic analysis was performed in which data was interpreted further using key factors from network governance. The results of two analyses are related and visualised in Table 3 . 


\section{RESULTS}

In the results section, we present first, the potential candidates, and thereafter the associated opportunities, challenges and needs structured by four different themes. The full list of identified needs can be found in Appendix 1.

\subsection{Potential candidates for semi-professionals in emergency response}

In the first Future Workshop, the participants proposed that semi-professional intervention in frequent emergencies might mitigate negative effects, control the situation and save people's lives. For example, a semi-professional may be able to control a fire in a garbage can near a building before it spreads to the building. They may arrive quicker than professional resources, especially in rural areas. Discussed potential candidates were security guards, home care, the Swedish church, village communities, fire services day personnel, private entrepreneurs (for example facility services), taxi drivers and bus drivers. The selection was based on factors such as availability of resources in the municipality, their ability to interrupt their current work when receiving alarms, their qualifications such as training, and the geographical spread of resources.

Based on the results from the Future Workshop, together with studies of previous research and other similar initiatives, the following four potential candidates were selected:

1) Security guards who inspect municipal facilities and respond to related alarms from their clients.

2) Home care personnel who are employed by the municipality. Their clients are mostly elderly living in their homes.

3) Facility services is a private company who are responsible for maintaining the municipal facilities, for example playgrounds and public buildings.

4) Fire services day personnel are employed by the municipal fire services but are not part of the response organisation. Instead, they work daytime with teaching, material procurement, and office work.

\subsection{Using semi-professionals: challenges, opportunities and actor needs}

\subsubsection{Theme 1: Responsibility, availability and attitude}

Opportunities: All respondents were, in general, positive about the potential new role of semiprofessionals. They regarded it both as development, an organisational bonus and as an emerging trend in society. The manager respondents ${ }^{1}$ pointed out the importance and need of cross-sector collaboration in future society. The security guards and home care saw working as a semi-professional as particularly interesting and exciting since it is very close to their current tasks.

\footnotetext{
${ }^{1}$ To refer to manager respondents, the word 'manager' is used, e.g. 'the manager respondent from the home care'. To refer to respondents from operative personnel only the word "respondent" is used, e.g. 'respondent from security guard'.
} 
The respondents, except home care, agreed that when receiving an alarm, in most cases they would be able to interrupt and leave their current tasks in about 5 minutes. The manager respondent from the facility service mentioned that they have fifty cars and are available in most parts of the municipality, but that they have few on-call resources at night. The manager from the security guards, on the other hand, said that they have more mobile resources during night time (about ten cars), compared to daytime ( one patrolling car) when most security guards are stationed at hospitals, shopping centres etc. The home care services have numerous resources spread all over the municipality, especially during daytime. However, in the city centre, many lack cars, and cannot travel long distances quickly. The fire service day personnel only work office hours and are mostly located at the fire stations. Some of them travel frequently all over the municipality. The respondents from home care and security guards named a variety of tasks they can do at the emergency site such as stopping simple bleedings, performing CPR, calming down shocked people, dispersing crowds, extinguishing smaller fires, placing warning triangles on the road at traffic accidents and helping injured individuals into a recovery position.

Challenges. The respondents claimed that it would be challenging to define and explain their responsibilities and tasks in an emergency. The facility service respondents, in particular, pointed out that they do not have any experience of emergencies and are not sure what they should do. The respondents also mentioned potential fear to take part in incidents, specifically in traffic accidents or complex medical emergencies. They expressed fear of not being able to manage the situation, of making a wrong decision and putting people's lives in danger instead of helping them (for example moving a person with a neck injury). One respondent from the fire service day personnel said:

"One must learn a lot about traffic rules; where to park [on a highway]. Where is it dangerous? I do not know as a private person if I would stop on E4 depending on the traffic [to help others in a traffic accident], it is very dangerous "

Needs. The respondents in the interviews and the fire services participants in the second workshop mentioned the importance of clearly defined expectations and responsibilities for the semi-professionals, and clearly defined tasks at an emergency. They emphasised the need to gain sufficient training to be a semi-professional. With such knowledge, they may overcome their fear and dare to act as first responders. The respondents from the facility services and security guards also said that there should be support for the semi-professionals, to handle potential stress, emotional or psychological consequences. The respondents (including the manager) from the facility services claimed that motivations such as higher salary might encourage a group of people (but not all) to partake in emergencies, while the other groups felt this would not be a good way to motivate people.

\subsubsection{Theme 2: Laws, regulations and work environment}

Opportunities. The respondents saw no need to change the current work setting to work as semi-professionals as long as the number of alarms is relatively low. According to the manager respondents, there is no formal organisational obstacle, regulation or law to prevent 
them from acting as semi-professionals in emergencies. For example, the manager of facility services said:

"Of course, if there is an accident or injury where we can help, surely we can dispatch our resources, it is possible for us and it does not feel at all strange to me."

Challenges. The respondents from facility services, however, stated it might sometimes be hard to prioritise between the new and their current task. For example, they said:

"[...] while fixing a big water leak in a school [...], we might receive an alarm about an accident nearby. To leave the school would lead to very big damage, but of course, if it is a matter of life and death you need to attend to it [the accident] first. But there can be complications."

Similarly, the home care respondents mentioned:

"You may think that it is easy to interrupt a stroll [to go and help others in an accident], but it is not possible to just leave an old person [client] in the street and walk away."

The manager from home care similarly argued that elderly clients are very dependent on home care employees and cannot manage themselves if employees often interrupt their tasks. The municipality organisation lacks sufficient flexibility to implement the collaboration smoothly since their personnel have a high workload.

The manager respondents emphasised that it is not clear who is responsible and what the consequences are, (for example insurance coverage) if a semi-professional is harmed at an emergency site or if a semi-professional unintentionally harms another person such as a victim. They also mentioned that there is no formalisation or particular law in the organisation or on national level concerning new cross-sector collaborations.

From an ethical point of view, some respondents from the home care and the fire services day personnel were not comfortable with being continuously positioned by a dispatch system.

Facility service respondents were worried that emergency victims might not trust them if they did not have some sort of uniform. Respondents from the facility service and the fire services day personnel claimed that traffic rules impose speed limitations hindering quick arrival when they drive their car to save somebody's life. For example, respondents from fire services day personnel said:

"I think it is a bit stressful [...]. You know that you are on your way [to help a dying person], but you cannot exceed the speed limit. “

The respondents claimed that being semi-professionals can include stress factors, i.e., it might be stressful to know that you might suddenly receive an alarm. They stated that the stress might prevent them from being able to perform their new tasks correctly, which might be harmful to themselves or others and/or cause sadness or depression.

Needs. The manager respondents emphasised the need to address and clarify all the challenges mentioned above. The fire services participant in the second workshop, in particular, pointed out the need for clarification about legal and ethical aspects of working as semi-professionals, regarding for example what they are allowed to do, how they should deal with alarm 
information, and what kind of insurance they need. The need for education about legal issues concerning the distribution of medicines and remedial actions was evident in the AAR.

\subsubsection{Theme 3: Training and emergency supplies}

Opportunities. Most of the respondents said that they had received some training in CPR, and some of them in basic firefighting as a part of their current employment contract. Respondents from home care knew that some of the home care personnel also had training as assistant nurses. Security guard respondents pointed out that they had been trained to act specifically as first responders. The fire services day personnel mentioned that there were actually a few of them who had worked as firefighters or fire engineers. Regarding equipment, all respondents except home care said that they have cars with equipment such as first aid kits and fire extinguishers. Home care respondents said that they have digital keys by which they can easily open their client's apartment doors.

Challenges. The respondents mentioned the difficulties of using previous training because they had forgotten, had not repeated it, or would not dare to use it in real situations. The manager of facility services claimed:

"... it [the training] is fresh the first year, however, then you start to forget. [...]. We have training in $C P R$ and similar types every four years, but like I said, it is not sufficient if we are expected to help in this way..."

Even if the respondents acknowledged that they had already received some training, this was not always true for the other employees working in their organisation. In particular, respondents from home care and fire services day personnel said that some employees had received only partial training or no training at all. Regarding equipment, respondents from the security guards and the facility service said that their cars do not have much space to locate additional emergency supplies. The manager respondents said that some equipment (for example defibrillators) is expensive and additional training is needed to use them properly.

Needs. The respondents stated the necessity to receive and update training in CPR and basic fire extinguishing at least once a year. They also wanted practical exercises with the professional resources every second year. The respondent from the fire services day personnel mentioned additional needs for training including training on traffic rules to act appropriately in traffic accidents, training in managing other people (shocked persons and injured relatives) at the emergency site, and familiarity with professional resources' routines to avoid conflict with their tasks. The fire services day personnel representatives in the second workshop mentioned concrete needs, such as learning to use the alarm management system, to perform risk assessment, and stress management. They also pointed at more advanced training for example about managing suicide cases and traffic accidents.

The respondents suggested a variety of equipment such as a smartphone for receiving alarms (while stressing that it should not be an additional device), blankets, reflective vests, and warning triangles. In the second workshop, the representatives from the fire services also identified pocket breathing masks, warning lights, and mobile phone car chargers. The 
manager respondents suggested defibrillators and extinguishing grenades, which were confirmed as helpful by the participants in the second workshop.

\subsubsection{Theme 4: Information Technology (IT) and communication}

Opportunities. The respondents emphasised their preference for mobile phone-based solutions for receiving alarms and for communicating with others. For example, they can use a smartphone application to receive alarms, and the phone camera to take photos of the emergencies. Respondents from home care and security guards said that they already receive work-related alarms concerning urgent events on their mobile phones. However, as they and other people in their organisation often have both private and work mobile phones, they were reluctant to add an additional device. The security guards also already had extra equipment for communication, such as handheld PCs.

In the exercise/simulated car accident AAR, the ambulance personnel acknowledged that the information that can be received from the semi-professionals being at the emergency site is useful also for themselves and the alarm centres. For example, if they receive the exact GPS positioning from semi-professionals that have already arrived at a traffic incident on the highway they might be able to determine in which lane the accident happened, which might help them arrive faster at the site.

Challenges. In a pure mobile phone-based system, the network coverage might be inadequate in some areas such as forests, rural areas, and basement of buildings. For example, the respondents from the facility services said:

\section{"[...] one problem can be when you are in the basement of buildings or are working in some} underground centres [...] and there is no mobile phone coverage. This can be a problem since you spend a lot of time there. At least I myself often work in underground centres."

One of the respondents pointed out that more comprehensive information systems are not an important part of their current job. Furthermore, they do not have any system of their own (such as an alarm management system or positioning systems to locate resources) that can be used in their new tasks. Lack of integration with the professional response organisation's system also became evident in the exercise, where the car accident victims acknowledged that they became stressed because they could not receive correct information from semi-professionals about when the ambulance would arrive.

Needs. All respondents pointed at the need for a stable communication channel and the possibility to talk to the alarm centre and the professional resources in case they need to get more information. They also emphasised the need for a dedicated IT system for receiving alarms, which should be integrated with their current mobile phones, for example in the form of an application. The system should provide short and exact information about the type of incident, a brief description of the incident, its location and provide navigation support. They also requested that the system should provide information about when professional resources will arrive. The respondents from the facility services and fire services day personnel said that the alarm signal should be loud and entirely different from other notification signals on the phone. The respondents from home care mentioned the possibility to send information (video, 
photos, and text) relevant in emergencies to the alarm centre or the fire services. Respondents from the fire services day personnel and home care pointed to the need for an acknowledgement function by which semi-professionals can inform others that they are at the emergency site. They also mentioned the need for a system in which they can inform the alarm centre whether they are available or not. For example, they may be in another city or on leave.

In the second workshop, representatives from the fire services day personnel confirmed all of the IT related needs. They also suggested a set of other functions, to support reporting after the response operation, to have a voice guide navigation, and to automatically inform the employers about interrupting the current task. A status function by which a semi-professional can inform others (e.g., the alarm central) when he or she is on the way, has arrived or need extra help were also viewed as important. Some other advanced functions such as voice-based instructions about the response operation, quick checklists about what a semi-professional should do in a specific emergency were also identified. In the exercise/AAR, new needs emerged, such as to adapt the smartphone application so that it automatically reports when a semiprofessional has reached the emergency site (since one of them forgot to do that).

\section{ANALYSIS: A NETWORK GOVERNANCE PERSPECTIVE}

This section presents the analysis of the results, using principles and key factors in network governance.

\subsection{Steering mechanism}

The study results showed that the fire services and potential semi-professionals indeed share interests in saving lives and helping others in emergencies. Semi-professionals can perform activities that reduce the negative consequences at an emergency site, but they are restricted in several aspects. For example, they are not allowed to give medicine to victims without delegations from healthcare organisations. They cannot perform smoke diving or act on fires where there is a risk of explosion because they do not have the required professional competence. Semi-professionals should follow the guidelines and training they receive from professionals, and are never substitutes. A certain degree of hierarchical government can thus be seen in their collaboration with fire services making it a hybrid form of network governance and governmental hierarchy.

\subsection{Collaboration and decision-making}

The results of the study confirmed potential benefits quite similar to those associated with network governance collaboration. For example, some respondents had relevant competencies for emergency response as well as a good geographical availability. Thus, including semiprofessionals in the emergency response network might significantly increase the number of available resources. However, semi-professionals do not have the same scope of action as fire services in emergencies. Furthermore, the collaboration is administered by fire services who has selected the specific incidents that semi-professionals can be dispatched to, and outlined their tasks and responsibilities. Thus, structural organisational factors and the Swedish law limit in several respects the horizontal and democratic decision-making. The new 
collaborations, in this case, seems closer to traditional governmental mechanisms than to network governance.

\subsection{Trust}

The results did not indicate trust to be a major obstacle among the semi-professionals themselves or in relation to the professional organisations. However, some actors (home care organisation and facility services) did not express full trust because of perceived ambiguities in actors' new tasks and responsibilities. The home care also expressed a need to create 'internal trust', i.e. trust within their own organisation between personnel, to increase the understanding of the new tasks/collaborations, and how they might influence their ordinary jobs. Also to clarify for the semi-professionals what might happen if they make mistakes, or just fail to make a valuable contribution. In summary, trust seems important in the collaboration and specifically in information sharing between actors. 'Internal trust' has rarely been discussed in network governance literature. Its perceived importance here is probably a consequence of cross-sector collaboration in emergency response having a more present governing mechanism than what is usually the case in network governance.

\subsection{Conflicts and institutional rules}

The study results showed ambiguities in responsibilities, the uncertainty of tasks and conflicts as to how they should be prioritised, incomplete laws and lack of insurances, fear of partaking in collaboration, and (sometimes) organisational cultures that do not support the semiprofessional assignment. Again, it seems that the majority of complexities stem from the lack of formalisation, institutional rules and a governance/administration mechanism in using semi-professionals.

A summary of the analysis in relation to the four identified themes is shown in Table 3.

Table 3. Similarities/differences between network governance and different aspects of semi-professionals involvement in emergency response

\begin{tabular}{|l|l|l|l|l|}
$\begin{array}{l}\text { Network } \\
\text { governance }\end{array}$ & $\begin{array}{l}\text { Semi-professional } \\
\text { responsibility, availability } \\
\text { and attitude }\end{array}$ & \multicolumn{1}{|l}{$\begin{array}{l}\text { Laws, regulations and work } \\
\text { environment }\end{array}$} & $\begin{array}{l}\text { Training and } \\
\text { emergency } \\
\text { supply }\end{array}$ & \multicolumn{1}{|l}{$\begin{array}{l}\text { Information } \\
\text { Technology }\end{array}$} \\
\hline Core principles & $\begin{array}{l}\text { Similarities: heterogeneous } \\
\text { actors with shared interests } \\
\text { Differences: existence of } \\
\text { implicit hierarchical control of } \\
\text { semi-professionals' actions }\end{array}$ & $\begin{array}{l}\text { Similarities: collaboration } \\
\text { between independent } \\
\text { organisations with their own } \\
\text { rules. }\end{array}$ & Not applicable & Not applicable \\
\hline $\begin{array}{l}\text { Collaboration } \\
\text { and decision- } \\
\text { making }\end{array}$ & $\begin{array}{l}\text { Similarities: collaborative } \\
\text { action problem solving. }\end{array}$ & $\begin{array}{l}\text { Differences: limited } \\
\text { democratic decision making } \\
\text { by semi professionals }\end{array}$ & $\begin{array}{l}\text { Supplies and } \\
\text { training not a key } \\
\text { factor in network } \\
\text { governance }\end{array}$ & $\begin{array}{l}\text { IT not a key } \\
\text { factor in } \\
\text { network } \\
\text { governance }\end{array}$ \\
\hline Trust & $\begin{array}{l}\text { Similarities: facilitator of } \\
\text { collaboration }\end{array}$ & $\begin{array}{l}\text { Similarities: can reduce } \\
\text { institutional complexities }\end{array}$ & $\begin{array}{l}\text { Supplies and } \\
\text { training not a key } \\
\text { factor in network } \\
\text { governance }\end{array}$ & $\begin{array}{l}\text { IT not a key } \\
\text { factor in } \\
\text { network } \\
\text { governance }\end{array}$ \\
\hline
\end{tabular}


Conflicts and institutional rules
Similarities:

complexities/conflicts, e.g. ambiguities in responsibilities, and to prioritise between tasks

Differences: additional factors such as 'fear' and 'motivation' may cause conflicts, not discussed in network governance
Similarities: Institutional rules/laws may compete and cause conflicts in the members' interactions

Differences: Ethical challenges not discussed in network governance
Supplies and training not a key factor in work governance

IT not a kay

\section{DISCUSSION}

In the following, we first discuss the opportunities and challenges of using semi-professionals in emergency response. We then address practical implementation of cross-sector collaborations. Finally, we discuss them as a potential form of public sector network governance and the transferability of the results to similar ERS/public sector settings.

\subsection{Emerging forms of cross-collaboration in emergency response}

Pooling the capability of different public sector resources has been attempted by involving various actors such as occupational groups, non-profit organisations, organised and spontaneous volunteers (Ramsell et al., 2017; Weinholt and Andersson Granberg, 2015; Pilemalm et al., 2013; Agranoff, 2007; Goldsmith and Eggers, 2004; Sund, 2006). As for cross-sector collaborations specifically, involving expert groups, communities and various occupational groups have been studied and even implemented internationally (Patton, 2007; Valenzuela, 2000). In emergency response, the importance of collaboration and involving redundant resources have been emphasised in previous research (Kapucu et al., 2010; Patton, 2007; Waugh and Streib, 2006). Still, the research area can be considered as new and emerging.

Our study indicates that semi-professionals indeed have the potential to increase the capacity of ERSs. For example, the studied groups had cars, basic emergency supplies, and often relevant training. They could perform basic but often vital actions in emergencies such as stopping a bleed or extinguishing a small fire before it spreads to buildings. It is reasonable to assume that this potential is not limited to the municipality of Norrköping. Most of the occupations studied are similarly organised in other Swedish municipalities, as well as in other countries. Thus, they probably also have the same basic needs for equipment (fire extinguishers, blankets, reflective vests, warning triangles, pocket breathing masks, warning lights, etc.) and training (CPR, fire extinguishing, traffic rules, risk assessment, etc.).

The major challenge identified in the study was ambiguities in semi-professionals' new tasks and responsibilities, and how to prioritise between tasks. Furthermore, organisational, legal, ethical and economic obstacles were identified. The challenges are in line with other studies which emphasise factors such as actors' level of experience, training, commitment and competence, legitimacy and insufficient categorisation of tasks (e.g., Ramsell et al., 2017, Pilemalm et al., 2016a; Palm and Törnqvist, 2008; Pelinka et al., 2004), thus indicating that they have relevance beyond Norrköpings municipality and the project scope. In particular, the complexity of the cross-collaborative actions manifests itself in prioritisation between current 
tasks and new tasks. Here, it is also possible to discern contradictions in the data set in that most semi-professionals, on the one hand, explained that they would have no problem responding to an alarm if the alarms are not too many; on the other hand, they also express obvious difficulties in leaving certain re-current tasks. The study displays several IT needs, in the project supported through a prototype smartphone-based application for alarm management for receiving and answering alarms. Mobile IT is a central pre-requisite for dispatching and supporting the semi-professionals. However, while the development of IT solutions in the study was perceived as rather straightforward once the user needs had been identified, the organisational issues posed many more challenges and are crucial to address if cross-sector collaboration in emergency response is to succeed.

\subsection{Implementing the cross-sector collaborations}

When implementing cross-sector collaborations in emergency response, both general and specific characteristics need to be identified and handled. When selecting the four groups to analyse in the study, the ability to interrupt their current tasks, their spatial and temporal availability, and existing relevant training and equipment were identified as vital factors. Some of the factors were occupation specific whereas other were location or municipality specific (for example a re-organisation of home care and the related difficulties to leave their elderly customers and how the security guards are stationed in the municipality). Therefore, the candidates selected should not be seen as those most suitable for any similar cross-sector collaboration. Rather, the selection process is necessary and should be performed actively and specifically for each ERS cross-sector collaboration context while criteria for the selection should be reviewed and updated. Similarly, structures and procedures for defining tasks and responsibilities and for supporting the prioritisation in a given situation must probably be identified for each selected occupational group. Nevertheless, the groups and factors identified in the study may be used as support in the selection and identification process. There are also other studies in other Swedish municipalities demonstrating successful outcomes of using security guards as first responders while pointing at several difficulties when engaging home health care nurses (Weinholt and Andersson Granberg, 2015). This may indicate that certain professions are easier to deploy and dispatch than others.

User and stakeholder participation is essential, both in the selection process, and in the ensuing work of identifying work tasks, responsibilities, needs etc. To work closely with stakeholders and users becomes fundamental to develop new public sector/ERS collaborations in which actors are heterogeneous, come from different organisations or sectors and where new tasks, challenges and needs are not defined and clear (Pilemalm et al., 2016b; Yousefi Mojir and Pilemalm, 2016). In our study, the joint effort of participants from the different organisations was deemed crucial to give insights into various aspects of cross-sector collaboration. For example, participants from the fire service had many ideas of how such collaborations may support emergency response while participants from the municipality could provide insights about administrative and organisational aspects. The potential semiprofessionals highlighted many challenges, for example regarding the prioritisation of tasks, which have to be solved. Moreover, the test of dispatching semi-professionals to a simulated traffic accident confirmed many of the previously identified needs. It also generated entirely new needs and helped to complete, concretise and enrich the results. Similarly, additional stakeholders 
must be involved (employers, alarm centres, national authorities, rescue services, unions, etc.) to clarify responsibilities and tasks of actors in the network in advance. This includes, for example, task documentation, agreements and ethical principles, providing insurance and, not least, guidelines for prioritising between tasks, and integrating specific IT support with the systems of the professional response organisations. Also in the ensuing development process, certain aspects such as motivation, organisational support, laws and competencies probably need to be investigated for each country, region, case or project context, while others are more general.

\subsection{New collaborations as a form of network governance}

From a network governance perspective, cross-sector collaboration in emergency response shows several similarities to factors identified as central to network governance, the most prominent including mutual interest between members for collective problem solving as a base for creating the collaborations, and the semi-professionals being autonomous with heterogeneous backgrounds and competencies. It also seems that many inherent complexities in network governance (conflict in strategies, ambiguities in institutional rules etc.) also exist in cross-sector collaboration. Also, even if trust within the network did not seem a major issue in our study, other studies show that trust might be an issue between professional and nontraditional resources, as, for example, between home care personnel and fire services (Jansson and Grip, 2016). Further, Klijn and Koppenjan (2014) claim that rules in a network can cause complexity if they become many but inconsistent, are not well understood by members, and conflict with other organisational and national laws. This is notable in our study as the lack of supportive laws and insurance for semi-professionals, caused ambiguities in associated responsibilities.

However, our study also implies that the cross-sector collaborations in other respects differ from traditional forms of network governance. Most importantly, semi-professionals did not have a pure horizontal interaction with the fire services and were restricted in action in different ways. The need for a steering mechanism to formalise the collaboration was evident and lack of steering mechanisms has actually been discussed previously as a weakness of network governance (Antivachis and Angelis, 2015). Also, the role of 'internal trust' between members of an organisation is not clearly visible in the network governance literature. However, from our study it is quite clear that lack of 'internal trust' may actually prevent organisations from taking part in the new collaboration and that it thus needs to be created and promoted.

There are also factors that seem vital to ERSs cross-sector collaboration, but not necessarily to network governance in general, for example the fundamental role of basic supplies and practical training collaborations, and means to handle stress and fear. To neglect them may risk lives or generate severe risks in terms of emotional and psychological damage for semiprofessionals as well as failure of the collaborations. From a theoretical perspective, it is also notable that these factors are at an individual level while network governance literature focuses mostly on an institutional level (Antivachis and Angelis, 2015). Furthermore, network governance literature does not explicitly include IT as a factor influencing the outcome of the networks. This has also been noted by other recent studies (Ramsell, et al. 2017) and the 
phenomenon reflects a more general discussion on how information systems and policy science can benefit from each other when applied to public governance, digital government, and public administration research (Gil-Garcia et al., 2017). For semi-professionals, basic IT support was identified as fundamental for dispatching and communication. Other identified needs include shared IT platforms for accessing incident data, smartphone apps, and portable map systems.

In summary, it seems that the emerging forms of cross-sector collaboration in emergency response can be seen as a hybrid of network governance and hierarchical government. Therefore, the institutional perspective provided by network governance may very well be applied to address collaboration key factors. In addition, there are specific, individual factors that need to be added to any analysis of ERSs cross-sector collaboration. Also, complementary theoretical perspectives will probably be needed, e.g. theories from policy network (Carlsson, 2000) and new public management (Gruening, 2001) to address the more substantial need for hierarchical governing mechanisms and regulations. Finally, although this is outside the scope of our paper, it is worth pointing out that since IT will most likely be a crucial part of any network collaboration ( as facilitator or hindrance) it might be beneficial to add it in future network governance theory development.

\subsection{Generalisation to other ERSs and public sector collaborations}

Our study applies specifically to the use of semi-professionals and cross-sector collaboration in emergency response. Considering our previous experiences and related research, the results may well be applied to other collaborations in ERSs, for example involving volunteers and bystanders, since these collaborations involve some similar characteristics such as autonomous resources taking on new and undefined tasks not formalized in current legislation and government mechanisms (e.g., Ramsell et al., 2017; Venema et al., 2010). In addition, since the ultimate goals are the same, i.e. saving lives and minimising environmental damages, and since they deal with similar types of emergencies such as fires, traffic accidents, heart attacks and drowning, the many identified needs might be applicable also to civil volunteers.

In a wider perspective, parts of the results might be reusable in other cross-sector collaborations in various public sector contexts. One example can be the need to improve health and education outcomes in remote communities with scarce professional resources (Jones et al., 2015). Healthcare might be especially relevant, in the cases where laws and rules concerning patients are similar to those in emergencies and lack of professional resources occur in rural areas when medical units are centralised and sometimes remote from small villages.

\section{CONCLUSIONS AND FUTURE WORK}

Natural disasters, humanitarian catastrophes, wars, pandemics and the threat from extremist groups put a huge strain on emergency response organisations in modern societies (Ingold and Fischer, 2014; Johnston and Finegood, 2015). At the very same time, they have to deal with continuous emergencies of smaller scale in times of urbanization, de-population in rural areas, ageing populations, budgetary cuts and resource shortage in the public sector. This has made 
emergency response organisations try to involve other societal resources, for example as first responders, and it is likely that this trend will prevail and expand, given societal development.

In this study, we explored the opportunities, challenges and actor needs in a recent crosssector collaboration initiative engaging various occupations in Swedish emergency response. The study also contributes with suggestions of semi-professional groups and a set of factors that should be considered when selecting the groups. The most important findings can be summarised as follows:

- Potential: Utilising semi-professionals might indeed increase the total capacity of the emergency response system and they might make a vital contribution in many emergency situations.

- Who: We identified four candidates as most suitable in the municipality (security guards, facility service technicians, home care personnel and fire service day personnel), and for the project implementation we ended up with the latter. It is important to remember that the choice of occupational groups may be dependent on the specific project, municipality, region or national context while some occupational groups likely are easier to deploy and dispatch than others.

- Challenges: The major identified challenges are organisational, economic and juridical and include handling ambiguities in responsibilities and tasks, regulations and insurance matters. To introduce some kind of formalisation and administration mechanism seems crucial, for example defining roles, tasks and responsibilities, writing contracts, procuring basic materials and starting petitions for changes in existing laws for supporting semiprofessionals as first responders. The most difficult to handle is probably the challenge of prioritizing between tasks, since the cross-sector collaborations imply that organisations need to take on new tasks with the same amount of resources.

- Needs: It is necessary to train and equip the semi-professionals and provide them with basic but proper support in in terms of emergency supplies and IT with them being dispatched using their own mobile phones. The major effort here is integration with the response organisations' own IT systems. It is also notable that many needs were similar across organisational groups.

The necessity of active involvement of the semi-professionals (end-users) and involvement of additional stakeholders in the development of the new collaborations cannot be underestimated. Actually, in our study, the participated actors also encouraged the municipality of Norrköping to start implementing the study results. For example, the fire services in the municipality have started to provide first response training for all fire service day personnel. The developed smartphone application was also used with minor changes in another project for testing collaboration between civil volunteers and fire services. At a national level, we have participated in governmental investigations on how to assess the use of semi-professionals in the future Swedish ERS.

Our study explored a situation where various occupational groups can be dispatched on the same type of alarms doing the same kind of first response. For the future, it would be useful to investigate whether, and if so why, certain occupational groups fit better for certain assignments. At a more practical level, the successive accumulation of knowledge about semiprofessionals may facilitate the creation of general checklists, needs lists, guidelines and how- 
to-do-it manuals to be applied in the implementation of cross-sector collaborations. On the theoretical side, ERSs can be characterised as a hybrid form of network and more hierarchical forms of governance. Network governance may thus be helpful when developing the institutional aspects of future cross-sector collaboration in emergency response, but future work should also incorporate other related theories, for example from public administration, new public management and policy networks theory. Similarly, important future work might include the development of methods and cost-benefit models to evaluate using semiprofessionals in emergency response.

\section{ACKNOWLEDGEMENT}

This study was partly funded by Norrköpings municipality, and partly by the Swedish Civil Contingencies Agency, through the research centre CARER (Center for Advanced Research in Emergency Response). 


\section{REFERENCES}

Agranoff, R. (2007). Managing Within Networks: Adding Value to Public Organizations. Georgetown University Press, Washington, D.C.

Alford, J. and O’Flynn, J. (2012). Rethinking Public Service Delivery: Managing with External Providers. Palgrave Macmillan, Houndmills, Basingstoke, Hampshire, New York.

Antivachis, N. and Angelis, V. (2015). "Network Organizations: The Question of Governance." Procedia Social and Behavioral Sciences, Vol. 175, pp. 584-592.

Babiak, K. and Thibault, L. (2009). "Challenges in Multiple Cross-Sector Partnerships." Non-profit and Voluntary Sector Quarterly, Vol. 38 No. 1, pp. 117-143.

Bolton, F. (2016). "Use of the After-Action Review to Improve Learning.” Assessment Update, Vol. 28 No. 2 , pp. 3-15.

Brinkerhoff, J. (2002). “Government-non-profit partnership: a defining framework.” Public Administration and Development, Vol 22 No. 1, pp. 19-30.

Bryson, J., Crosby, B. and Stone, M. (2006). "The Design and Implementation of Cross-Sector Collaborations: Propositions from the Literature.” Public Administration Review, Vol. 66, pp. 44-55.

Bryson, J., Crosby, B. C., Stone, M., and Saunoi-Sandgren, E. (2009). "Designing and Managing Cross-Sector Collaboration: A Case Study in Reducing Traffic Congestion." Washington, DC: IBM Center for the Business of Government. Available at: http://www.businessofgovernment.org/sites/default/files/Designing and Managing.pdf (accessed October 2017).

Carlsson, L. (2000), "Policy Network as Collective Action” Policy Studies Journal, Vol. 28 No.3, pp. 502-520.

Drezner, J., Rao, A. , Heistand, J., Bloomingdale, M. and Harmon, K. (2009). "Effectiveness of Emergency Response Planning for Sudden Cardiac Arrest in United States High Schools With Automated External Defibrillators." Circulation, Vol. 120, No. 6, pp. 518-525.

Fischer, P., Krueger, J., Greitemeyer, T., Vogrincic, C., Kastenmüller, A., Frey, D., ... Kainbacher, M. (2011). "The bystander-effect: A meta-analytic review on bystander intervention in dangerous and nondangerous emergencies." Psychological Bulletin, Vol. 137 No. 4, pp. 517-537.

Gazley, B. and Brudney, J. (2007). "The Purpose (and Perils) of Government-Nonprofit Partnership." Nonprofit and Voluntary Sector Quarterly, Vol. 36 No.3, pp. 389-415.

Gil-Garcia, J., Dawes, S. S., and Pardo, T. (2017). "Digital government and public management research: finding the crossroads." Public Management Review, pp. 1-14.

Goldsmith, S. and Eggers, W. D. (2004). Governing by Network: The New Shape of the Public Sector. Brookings Institution Press and the Innovations in American Government Program at the John F. Kennedy School of Government at Harvard University, Washington, D.C.

Greve, C. and Hodge, G. (Eds.). (2005). The Challenge of Public-Private Partnerships: Learning From International Experience. Northampton, Mass: Edward Elgar Pub, Cheltenham, UK.

Gruening, G. (2001). "Origin and theoretical basis of new public management." International Public Management Journal, Vol. 4 No. 1, pp. 1-25.

Hamann, R., Giamporcaro, S., Johnston, D. and Yachkaschi, S. (2011). "The role of business and cross-sector collaboration in addressing the 'wicked problem' of food insecurity." Development Southern Africa, Vol. 28 No. 4, pp. 579-594.

Hollenberg, J., Riva, G., Bohm, K., Nordberg, P., Larsen, R., Herlitz, J., .. Svensson, L. (2009). "Dual dispatch early defibrillation in out-of-hospital cardiac arrest: the SALSA-pilot.” European Heart Journal, Vol. 30 No. 14, pp. 1781-1789.

Ingold, K. and Fischer, M. (2014). "Drivers of collaboration to mitigate climate change: An illustration of Swiss climate policy over 15 years." Global Environmental Change, Vol. 24, pp. 88-98.

Jaeger, P. T., Shneiderman, B., Fleischmann, K. R., Preece, J., Qu, Y. and Fei Wu, P. (2007). “Community response grids: E-government, social networks, and effective emergency management." Telecommunications Policy, Vol. 31 No. 10-11, pp. 592-604.

Jansson, U., Grip, L. (2016). "Rätt man på rätt plats! Kommunala sambruksprocesser ur ett genusperspektiv. [Right person in right place! Co-operative use of municipal resource from a gender perspective]", Unpublished Manuscript. MSB [Swedish Civil Contingencies Agency], MSB Report MSB962, ISBN 
Semi-professionals: emergency response as an additional task in current occupations, International Journal of Emergency Services, https://doi.org/10.1108/IJES-11-2017-0059.

978-91-7383-635-7, Karlstad

Johnston, L. and Finegood, D. (2015). "Cross-Sector Partnerships and Public Health: Challenges and Opportunities for Addressing Obesity and Noncommunicable Diseases Through Engagement with the Private Sector.” Annual Review of Public Health, Vol. 36 No. 1, pp. 255-271.

Jones, C., Hesterly, W. and Borgatti, S. (1997). "A General Theory of Network Governance: Exchange Conditions and Social Mechanisms.” The Academy of Management Review, Vol. 22 No. 4, pp. 911945.

Jones, D., Lyle, D., Brunero, C., McAllister, L., Webb, T. and Riley, S. (2015). "Improving health and education outcomes for children in remote communities: A cross-sector and developmental evaluation approach." Gateways: International Journal of Community Research and Engagement, Vol 8 No. 1.

Jungk, R. and Müllert, N. (1987). Future Workshops: How to Create Desirable Futures. Institute for Social Inventions, London, UK.

Kapucu, N., Arslan, T. and Demiroz, F. (2010). "Collaborative emergency management and national emergency management network." Disaster Prevention and Management: An International Journal, Vol. 19 No. 4, $452-468$.

Klijn, E. and Koppenjan, J. (2012). "Governance network theory: past, present and future." Policy and Politics, Vol. 40 No. 4, pp. 587-606.

Klijn, E., Edelenbos, J. and Steijn, B. (2010). "Trust in Governance Networks: Its Impacts on Outcomes." Administration and Society, Vol. 42 No. 2, pp. 193-221.

Klijn, E. and Koppenjan, J. (2014). "Complexity in Governance Network Theory." Complexity, Governance \& Networks, Vol. 1 No. 1, pp. 61-70.

Klijn, E (2008). “Governance and Governance Networks in Europe.” Public Management Review, Vol. 10 No. 4, pp. 505-525.

Myers, M. (2009). Qualitative Research in Business \& Management. SAGE Publications Ltd, Los Angeles.

O'Leary, R. and Bingham, L. (2009). The Collaborative Public Manager: New Ideas for the Twenty-first Century. Georgetown University Press, Washington, D.C.

Palm, J. and Törnqvist, E. (2008). "Governing the sea rescue service in Sweden: communicating in networks." Journal of Risk Research, Vol. 11 No. 1, pp. 269-280.

Patton, A. (2007), “Collaborative emergency management”, in Waugh, W.L. Jr and Tierney, K. (Eds), Emergency Management: Principles and Practice for Local Government, ICMA, Washington, DC, pp. 71-85.

Pelinka, L., Thierbach, A., Reuter, S. and Mauritz, W. (2004). "Bystander trauma care-effect of the level of training." Resuscitation, Vol. 61 No. 3, pp. 289-296.

Pilemalm, S., Lindgren, I. and Ramsell, E. (2016a). "Emerging forms of inter-organizational and cross-sector collaborations in e-government initiatives: Implications for participative development of information systems." Transforming Government: People, Process and Policy, Vol. 10 No. 4, pp. 605-636.

Pilemalm S., Lindgren I. and Ramsell E. (2016b). "Fourth Generation of User-centered Design - Developing for E-government and Cross-sector Collaborations". Electronic Government and Electronic Participation, Vol. 22, pp. 178-192.

Pilemalm, S., Stenberg, R. and Granberg, T. A. (2013). "Emergency Response in Rural Areas" International Journal of Information Systems for Crisis Response and Management, Vol. 5 No. 2, pp. 19-31.

Powell, W. W. (1990). "Neither market nor hierarchy: Network forms of organization". In B., Staw and L., Cummings (Eds.), JAI Press, Greenwich, CT, Vol. 12, pp. 295-336.

Ramsell, E., Pilemalm, S. and Andersson Granberg, T. (2017). "Using Volunteers for Emergency Response in Rural Areas - Network Collaboration Factors and IT support in the Case of Enhanced Neighbours". In the Proceedings of the 14th International Conference on Information Systems for Crisis Response and Management (ISCRAM), Albi, Occitanie Pyrénées-Méditerranée, France, ISCRAM association, pp. 985-995

Reason, P. and Bradbury, H. (Eds.). (2013). The SAGE Handbook of Action Research: Participative Inquiry and Practice (Second Edition edition). SAGE Publications Ltd, London.

Rhodes, R. a. W. (1996). "The New Governance: Governing without Government”. Political Studies, Vol. 44 No. 4, pp. 652-667.

Stake, R. E. (2000) “Case Studies”, in Denzin, N. K. \& Lincoln, Y. S. (Eds.) Handbook of Qualitative Research, 
Sage Publications, Thousand Oaks, CA, pp.435-454.

Sund, B. (2006). "Sambruk av samhällets jour- och beredskapsresurser är lönsamt![ Is cooperative use of the on call and emergency standby resources profitable?]”. Report, PUBP21-466, Räddningsverket [Rescue Services Agency], ISBN 91-7253-298-X, Karlstad.

Thomson, A. and Perry, J. L. (2006). “Collaboration Processes: Inside the Black Box.” Public Administration Review, Vol. 66, pp. 20-32.

Valenzuela, T., Roe, D., Nichol, G., Clark, L., Spaite, D., and Hardman, R. (2000). "Outcomes of Rapid Defibrillation by Security Officers after Cardiac Arrest in Casinos." New England Journal of Medicine, Vol. 343 No. 17, pp. 1206-1209.

Venema, A. , Groothoff, J. and Bierens, J. (2010). "The role of bystanders during rescue and resuscitation of drowning victims." Resuscitation, Vol. 81 No. 4, pp. 434-439.

Waugh, W. and Streib, G. (2006). "Collaboration and Leadership for Effective Emergency Management.“ Public Administration Review, Vol. 66, pp. 131-140.

Weber, E. and Khademian, A. (2008). "Wicked Problems, Knowledge Challenges, and Collaborative Capacity Builders in Network Settings." Public Administration Review, Vol. 68 No. 2, pp. 334-349.

Weinholt, A. and Andersson Granberg, T. (2015). "New collaborations in daily emergency response: Applying cost-benefit analysis to new first response initiatives in the Swedish fire and rescue service." International Journal of Emergency Services, No. 4 Vol. 2, pp. 177-193.

Weisfeldt, M., Sitlani, C., Ornato, J. , Rea, T., Aufderheide, T. , Davis, D., ... ROC Investigators. (2010). "Survival after application of automatic external defibrillators before arrival of the emergency medical system: evaluation in the resuscitation outcomes consortium population of 21 million." Journal of the American College of Cardiology, Vol. 55 No. 16, pp. 1713-1720.

Yousefi Mojir, K. and Pilemalm, S. (2014). "Emerging communities of collaboration: co-location in emergency response systems in Sweden." In Proceedings of the 11th International ISCRAM Conference, Penn State, USA, ISCRAM association, pp. 546-555

Yousefi Mojir, K. and Pilemalm, S. (2016). “Actor-centred emergency response systems: a framework for needs analysis and information systems development." International Journal of Emergency Management, Vol. 12 No. 4, pp. 403-434. 


\section{APPENDIX 1: SEMI-PROFESSIONALS' NEEDS FOR TRAINING, EMERGENCY SUPPLY AND IT SUPPORT}

\section{Needs for Training}

General emergency response systems information

Semi-professionals' responsibilities and obligations

Alarm management system, e.g. via mobile app

Traffic rules and how to drive to an emergency site (e.g. rules about speed limits)?

First Aid

Cardiopulmonary resuscitation (CPR)

Traffic accidents management

Basic firefighting

Risk assessment of incidents

To manage shocked victims and observers who are present at emergency sites

Legal/ethical obstacles and limitations when performing response operations, e.g. medical actions

Information confidentiality, handling and sharing

Stress management

\begin{tabular}{|l|}
\hline \multicolumn{1}{|c|}{ Needs for Emergency Supply } \\
\hline Fire extinguisher \\
\hline Pocket mask (CPR pocket mask) \\
\hline Warning triangle \\
\hline Reflective vest \\
\hline First-aid kit \\
\hline Warning tools, e.g. warning lights \\
\hline Lifebuoy \\
\hline Car mobile charger / extra battery \\
\hline Blanket \\
\hline Checklist containing important actions at the emergency site \\
\hline Extinguishing grenade (if possible) \\
\hline Defibrillator (if possible) \\
\hline
\end{tabular}

\section{Needs for information technology support}

A smartphone-based application for receiving and answering alarms

To receive important information (address, position, type of incident, short description of incidents) via the application

To receive extra information (approximate time of professional, or other semi-professional, resources arrival, security code to buildings, needed emergency supplies) via the app

Navigation functions using digital map systems

Acknowledgement function to accept or reject a received alarm

To be able to check out, e.g., travelling or on leave.

Quick checklist of first essential actions based on the incident type (integrated into the application) 
Status reporting function for sending information to alarm management centre to confirm if a semiprofessional is on the way, has arrived, been delayed, or need extra help (including automatic arrival notice)

Loud and entirely different alarm signal than for other applications

Feedback report function to be used after response operations

Function to directly call the alarm centre or professional response resources

Voice-based navigation

Voice-based instructions

Functions to send video, photos, text to the alarm centre or to other resources 